\title{
Social Media and The Corrosion of Public Discourse: A Critique on The Rhetoric of Post-Truth
}

\author{
Sankhadeep Chattopadhyay
}

\begin{abstract}
The exponential acceleration of 'humbug' inside the social media has blurred the thin lines between 'opinion', 'fact' and 'truth' and has become a cradle of toxic polarisation. Social media, being one of the most popular and celebrated forms of consumer culture, possesses an unthinkable potential to congregate and gather information from people and distribute them in lightning-fast speed. While by distributing information in one hand social media promotes its efficiency and by diluting itself in the labyrinths of opinions on the other hand it reflects a constant practice of the straw man fallacy. The customised news feeds on social media not only fortifies 'truth' from the presuppositions of the mass but also license them to dwell inside a straitened silo. Social media, under the surveillance of Artificial Intelligence [AI], has made 'truth' an endangered species and also fostered a strategic deployment of 'lies'. This paper aims to offer a conceptual understanding on the rhetoric of 'post-truth', its types and how it corrodes public discourse by discombobulating the representation of 'facts' inside the media environment and further, envisages on the aspects of enclasping post-normal conversations and its possible effects on democracy, state and humanity.
\end{abstract}

Keywords: Post-truth, Fact, Opinion, Social Media, AI.

\section{Introduction}

For sustainable human development, the field of humanities have always encouraged multifarious cross-disciplinary communications, whether it is specialised or non-specialised, it's always been seen as a desirable advancement towards the future of humanities. Menand (2005) suggests, "the humanities are the study of life in its cultural dimension, which happens to be the dimension in which every human being actually operates" (p. 14). On this note, it can be said that in the advanced age of technocracy this cultural dimension is governed by a culture of 'enablement'. In our rapidly changing world of constant technological growth, production and reproduction, humankind has adapted a vulnerable space between the technological 'power' and 'control'. The exponential growth of 'new-media' helps facilitate the mass to dwell inside a vulnerable silo by providing them with a culture of 'enablement' by creating an epistemically hostile environment populated with bias thoughts, Facebook and Twitter bots, liars, bullshitters and several other dubious information sources. The knowledge and information that media produces these days is nothing but a design of discontent for the promotion of some interest groups and political platforms. The steady progression in digital humanities, as a combination of computational tools and traditional humanities, have finally become able to figure out various reasons for the partisan bias, which motivates to seek for the counter-narrative to combat all sorts of lies.

Any sort of lies possess a dangerous potential to balkanize any form of political 
culture, it's so, because, 'lies' can never simply appear and take hold of some political discourse, they have an idiosyncratic value attached to the corrosiveness of public policy. In order to take hold, a 'lie' must be introduced, developed and nurtured into the public discourse. At the most fundamental level, they disrupt the public trust and shake their belief in any given political system, channelizing the people of the respective state to lose faith in their government. These sorts of lies are not any random misrepresentation of any statements but well embroidered and dexterously skilful by nature-possessing an intrinsic resistance from falling under the category of transparent mendacity - and thus, becomes a popular version of 'truth' or rather a 'vulnerable truth'. On the very outset, these wilful lies have their motif hidden beneath the distraction of public eye from the real debate and to make any kind of ideological consensus impossible. Over last few years, especially in the political realm, it has been observed that there are some agencies whose motif is to make wilful lies which are solely focused on some subverted propaganda to obfuscate the objective version of the truth and has an iniquitous desire to hack the democracy of the nation by manipulating political practitioners, especially those, who believe that until there is any truth there can be no progress. This kind of approach echoes the reign of the Catholic Church, which used to promote the extended version of any statement that can be considered as a truth. This tendency of projecting the truth has been adapted by modern marketing techniques of the twentieth century, where the delivery of any sort of message is so perfectly crafted that it seems to be grounded in reality. An example can be drawn from the Victorian era, where these sorts of practices were not very rare. An enthralling account of Victorian mendacity and nonsense can be found in Anthony Trollope's The Way We Live Now, published in 1875. In the first chapter of the book, we see that Lady Carbury beseeches three different editors to commission good write-ups of her first book. That obviously refers to the corrupted system of reviews. It has been seen over the past few decades, especially in America, that the corporate sectors and few ideological interest groups have become extremely skilful to manipulate the press to serve their policy goals. While serving the policy goals these groups mud any 'fact' very tendentiously in order to create a political climate where 'truth' no longer exists or there are two opposing versions of the 'truth'. This tendency can corrode any sort of public discourse and it's beyond the public reach to trace where the falsehood originates. This motif basically helps the media to fertilise and distribute lies. Media doesn't create a lie but coordinates a strategic assault that is designed to hide the truth which eventually leads to public-controversy. In this way, the real progress of a democratic nation can be halted. These sorts of misrepresentations have the potential to undermine the basic democratic ideals of people. According to Rabin-Havt (2016) these industry-based lobbyists, the PR companies and medias who have popularised these kinds of lies are just "unethical experts" and "unscrupulous think tanks" (p. 6). The tyranny of interest groups was monstrously active since the Obama presidency in the USA. It was significantly noticeable in Obama's reign that whenever he came out with any sort of policy that could challenge the interest groups and energy companies, he encountered a litany of lies and distorted facts from his anti-lobby who had produced myriads of fake research by using a set of methodologies that actually turned out as a point of discussion and vulgar memes, then they were repeated on the TV programmes, propagated through the social media and hammered into the public consciousness by some private advertising campaigns whenever needed.

\section{Fact, Opinion, Truth and Its Aftermath}

The postmodern concept of the fragmentary nature of truth and the possibility of its representation in several methods were introduced and practised decades ago by the writers and activists like Virginia Woolf, James Joyce, Vladimir Nabokov, Joseph Conrad and Ford Madox Ford. They have shown us the unreliable nature of a narrator who is usually driven by 
whimsy and yearns for his subjectivity. As we all know that the term 'post-truth' craved a space in the Oxford English Dictionary (2016) as its word of the year and it's because of the rampant increase of the term's usage since the year of 2015 and its applicability to recent political events like 'Brexit' and the 'Presidential Election of the United States, 2016. The politics of 'post-truth' has its motif overlaid with obfuscating or discrediting the objective facts, which basically serves as political strategies and simply kindles to offer a bunch of 'alternative facts' instead of leading the mass towards the objective version of the truth. In order to go into the further detail let's briefly look into the basic differences between fact, opinion and truth, because the subtle divergence between these three terms has produced a space for what we may call a sociological masculine performance in the arena of politics and social media.

While a 'fact' has its unique quality to be proved, 'opinions' haven't had such statistical and mathematical sharpness. The term 'truth', apart from all its philosophical dimensions, possess a quality of being in complete agreement with fact, reality or the body of real things. It's quite interesting to notice the major shift that took place through times while the term 'post-truth' has become so popular. 'Post-truth' earlier used to denote something after the truth that is known. Now when seen from the contemporary perspectives the term 'post-truth' signifies something which only seems to be true and doesn't discover 'facts'. As I have already discussed in the introduction that behind this major shift from 'truth' to 'posttruth' there are various social agencies like the media corporations and others which cast spectacles and sensationalism as methods in order to capture the attention of the public by forming a toxic polarity and framing different opinions inside the social media. Eventually, the polarized media environment provides people a belligerent impetus to cheer for majoritarianism. This tendency, predominantly supported by the media eco-system, drags public into the vicious loop of disputation. It's a harsh fact that 'facts' have become a social construction in post-truth world. Hence, the 'social media reality', we encounter every day is nothing but a subjectively influenced sphere of objective truth.

\section{The Despotism of Alternative Facts in Media Culture}

Internet doesn't care about the impression that is being circulated, it remains completely impartial and cannot also restrict the factual inaccuracy in contents. It's so because the internet is run and driven by 'algorithms' and provides the easiest digestible contents that are available in the virtual world. Now, it's the media, who can congregate and accumulate the information from a large-scale variety and dispense them. Social media has a divine gift of efficiency for transportation of information. By circulating news and information in an electrifying speed they qualify, according to Davis (2018), the "economies of scale"(1). Standing in this structural condition media basically filters the information, as they are in charge of segregating the binaries like 'good/bad', 'true/false', 'monotonous'/'entertaining' and et cetera, before showcasing news virtually. Online platforms like Facebook and others are deceptive enough to dilute themselves in the labyrinth of opinions and only share us the filtered alternative facts. These online communication houses help people sequentially to form a gigantic straw-man of the opposing opinions so that the weaker ideas pangs to thrive and fades away. The stronger and rousing ideas slowly take hold of the quotidian 'social media reality'. In this way the media consumers becomes, as Ardent (1962) would suggest, an "ideal subject of totalitarian rule... for whom the distinction between fact and fiction (i.e., the reality of experience) and the distinction between true and false (i.e., standards of thought) no longer exists" (p. 474). Social media, while nurturing the polarity inside virtual space, reflects a 'Rashomon effect', which is a kind of phenomenon where a singular event has multiple interpretations at the same time from different individuals. The Japanese film 'Rashomon' (1950) by Akira Kurosawa has made us seen how the most entertaining version of truth turns out to be a near-lie or 'un-truth' and sustains longer and also becomes an edible 
version to the common mass. To analyse it deeper let's focus on some famous examples of the alteration of facts inside social media that had left corrosive impacts on the public discourse.

Davis (2012) has studied one of the most famous lies in the British Political Campaign made by Boris Johnson, the British politician, historian, and journalist and a member of Parliament in the United Kingdom. And that was, "we send the EU [European Union] 350 million euro a week" (Davis, 2012). It was a wilful distortion of facts presented with a motif of deception by Mr. Johnson. It was an embellished speech made in the "Vote Leave Campaign' in the British European Referendum. On the very first-hand Mr. Johnson was very much aware of the fact that Britain doesn't send that amount to Brussels, because the rebate was won by Thatcher in 1984 and that helped Britain to reduce the amount to two hundred and fifty million euro as its net weekly payment. So, the amount that Mr. Johnson claimed was certainly notional and addressed the emotive aspects of public so that they can be titillated on the base of some fictional amount that has a relation to their economic status which they maintain for the welfare of the state. Johnson's statement didn't take much time to go viral in social media and as an aftermath, we saw the events like Brexit. It's a classic example of 'post-truth', where a lie is developed and nurtured into the public discourse with the help of media and gives birth to an event fortified within the walls of deceptive information while sharing no value for the 'objective truth'. Another recent example can be given from the Asian News International's tweet on October 28, 2018. They posted a glimpse of speech by Mr. Shashi Tharoor that was delivered in the Bangalore Literature Festival. The tweet follows:

"Shashi Tharoor in Bengaluru, says, "There's an extraordinarily striking metaphor expressed by an unnamed RSS source to a journalist, that, "Modi is like a scorpion sitting on a Shivling, you can't remove him with your hand \& you cannot hit it with a chappal either."' (ANI, 2018)

After this event, the post went viral and mistakenly granted as a harsh remark made by $\mathrm{Mr}$. Tharoor that is venomous enough to hurt the sentiment of crores of people in India who worships Lord Shiva and simultaneously portrays a disgraceful image of the Honourable Prime Minister of India. Mr. Tharoor faced a litany of criticism in both in and outside of social media and was accused by many political leaders. While the news was being circulated on social media, the fact checking organization- 'altews.in' came out with an extensive research of the event that had taken place in reality. Their research puts in front a heedful look at Tharoor's speech which makes clear that it was not Tharoor's direct remark to the Prime Minister, he just quoted an unidentified RSS leader named Vinod Joshi who, while giving a news-bite to the executive editor of the Indian Magazine- 'The Caravan', said that statement. By the grace of some fact checking organizations a kind of combat zone has been created against such 'fake-news', 'alternative facts' and 'fake research' in the digital platforms, so that people can have access to the subversive layers of truthfulness of random facts that outspreads social media in a particular time. In this way media plays the role of a deceiver who doesn't want to act in a morally reprehensible manner and just wants to get away with its deceit. It's the social media network which has deliberately taken the responsibility, based on the algorithms, to provide news which are only popular and trending rather than specific or significant in order to form a stratagem inside the media environment.

\section{Measuring Truth and The Limits of Mendacity in Post-Truth World}

"Truth is the most valuable thing we have, let us economise it" - (Mark Twain, Following the Equator: A Journey around the World, 1897).

Economy has a strong relation with any kind of concept related to measurement. Rhetorical manipulators have a motif to measure the amount of truth in a sentence before 
delivering it. In order to avoid too much of the 'truth' the manipulators actually outright 'lying'. According to Burke (1878/1999),

Falsehood and Delusion are allowed in no case whatever: But, as in the exercise of all the virtues, there is an economy of truth. It is a sort of temperance, by which a man speaks truth with measure that he may speak it the longer. (p. 151)

In relation to this context, Davis (2018) has exemplified Mr. Tony Blair's inflammatory speech before the Iraq war of 2003 - which is considered as one of the most famous mendacious statements in the political history of Britain - as a kind of "deception through self-delusion" (p. 24). Mr. Blair's advocacy on Hussain's possession of nuclear weapons was undoubtedly a personal assessment made by emphasising on the 'doubt' that the British intelligence sectors had about Iraq. Davis (2018) describes the case like this;

If someone sincerely believes what they say, they are not lying when they say it, and it's perhaps unfair to say they are trying to deceive us exactly... but they are trying to convince us of something that is untrue, and the outcome is indistinguishable from instances when they are trying to be mendacious. (p. 24)

Black (1985) has suggested a 'humbug' as, "deceptive misrepresentation, short of lying, especially by pretentious word or deed, of somebody's own thoughts, feelings, or attitudes" (p. 143). The word 'humbug' has a motif hidden underneath its very countenance and that is the 'deliberate deception'. Black also says that it's not only a category of speech but also a category of action. On the contrary a 'bullshit' is phoney by nature as Frankfurt (2009) has explained that, a 'bullshit' "entails accepting standards and limitations that forbid the indulgence of impulse or whim" (p. 22). In the era of post-truth a culture of mendacity prevails by gradually forcing us to live inside the social media space, only for role-playing through the motif of its deception, which leaves a direct impact on the public relation. It's a rhetorical ploy through which social media transforms any 'objective truth' as its biggest enemy. Here, inside the virtual space the narratorial ambiguity attaches itself to the value of truth and provides a series of unwrinkled lies in an efficacious way. Rightly does Frankfurt (2005) says,

When we characterise talk as hot air, we mean that what comes out of the speaker's mouth is only that. It is mere vapour. His speech is empty, without substance or content. His use of language accordingly to the purpose it purports to serve. (p. 42)

There is a razor-sharp focus rests behind any act of mendacity that forms inside a given system of belief. Inside the virtual space, especially inside social media, this kind of deceptive attitude makes us realise that mendaciousness has itself become a yardstick of cultural norms, it is self-encouraging and possesses such a hypnotic charm that once inside its loop it's terribly hard to find the exit.

\section{The Apotheosis of Technocracy and The Future of Humanities}

Humanities, which is purposefully unstructured, give us our language by which we tactically convert our emotions to thought and action. Now in one hand, the third millennium has woke up to the need of empowering the machine learning processes, while on the other, the communication technology has reflected a rapid value neutral development. The degree of flexibility to accomplish different and complex goals has become a framework for the artificial intelligence $[\mathrm{AI}]$; which can relentlessly attain to its goals while being incredibly intuitive. Not only in their scientific build up but also the language and communicative programming of $\mathrm{AI}$ is considered as its future cornerstones. But, human ethicality is not one of the complex goals that AI can attain and it yet has to master the languages, codes and conducts of 'human ethics'. Since the palette of admissible ethical standards in humanity contradicts in a range of variety and moral judgements are subjected to individual rightsespecially their roles in the society and their motives and intentions-hence, it's a sheer challenging task for the engineers and developers to install properly any quantifiable codes of 
human-morality inside the AI. The discursively augmented reality of post-truth world has enforced a malicious mediatisation over the social networks and its news productions, turning the notion of labour upside down by immersing the humanity into a "culture of search" (Kalpokas, 2018). Searching for news and information used to be a resource intensive and laborious activity but nowadays it has substituted by a continuous act of scrolling down the screen. The social-world is entwined with mediatised communication and eclectically provides multiple forms of social interactions which remain ungoverned by time and space. The progressed and digitalised humanitarian affairs that we experience today is nothing but a design of mayhem that gets nurtured into the collective consciousness of the common mass who are simultaneously attached in a virtual realm and alienated in their physical-reality. This alienation resembles a kind of an enforced encroachment into the straight motif of human intelligence that was meant to be offered for human evolution. Especially, media has become a transformative zone of ethicality for modern human beings where they are prone to selfdeception as well. It has been observed in contemporary times that intelligent species can compete and survive in modern world because of their quality of self-deception which is perhaps an evolved feature of humankind. Not only the social domains are mediatised these days but also, as Kalpokas (2018) suggests, "the self is as well” (p. 59). Kalpokas's findings has put forward two firm reasons behind the mediatisation of the 'self', first one takes place through our digital (re-)presentations and the second one is through the amount of data our digital selves contribute by its digital footprints to the private organisations, exploiting which the corporations access a constant profit chain. Kalpokas (2018) explained how the blurring of an actual 'self' and the digital 'self' severely contributes to the world of post-truth;

"In the more everyday sense, the substitution of face to face communication with its technologically enabled mediatised version has already changed communication from an interhuman to that between digital-doppelgangers or between our doppelgangers and digital system of various bodies and institutions" (p. 60).

Now, an anxious query can be raised that how beneficial would it be to share this world with more intelligent species than humans, would it be a complete safe progression for humanity, state and democracy or an ominous appeal from the other side of the digital world. As because, every time our digital doppelgangers access the news-feeds and information over the internet which is already algorithmically structured by the AI, they are acquiring a digital presence of mind on their own, accessing all the social media accounts of a real human being. This alarming condition has severally been noticed by myriads of liberal humanists, scientists and anthropologists that by inventing the most superior form of communication, i.e., AI, human beings have made a serious discount on the aspect of 'emotion'. AI has multifarious sides of its prevalence, be it through the command of algorithms or some mechanised speech guidance, AI possesses a unique power to form a language of its own once transcended from the limitation of human language code. This feature is worthy enough to be claimed as an apotheosis of technocracy because no other technological inventions have such eloquent smartness as far like 'AI'.

\section{Conclusion}

Collective endeavours of competitive anger inside the social media is just a result of the confusing origin of truth and is a special modus operandi to justify millions of opinions. Social media has given innumerable freedom to air and share people's subjective views. In these open grounds of spontaneous thought sharing each individual voice wants to make their opinion heard by refuting other thoughts and opinions. This cacophonous tussle inside the media space reflects a 'Lombard effect'(2), where the phoney message management provides more noise and less information and where the public takes confidence in their own individual feelings and consider them as the only receiver of real knowledge without looking 
at the thoughts and beliefs of other people. In this way the actual motif of communication gets lost and it fails to make its value established in order to promote some aspects of truth.

As we have acknowledged throughout the progression of post-modernity that the idea of grand narrative no longer exists, hence, there is no fixed denotating structural meaning where some discourse or idea can be located particularly. In order to hint at some structural authority or at least the verisimilitude of it, we need to excavate the interpretation more than believing in the existing interpretation of the truth. The post-2016 world has seen and become aware of the multifarious aspects of fact representations and its effect on the state and democracy. In an era of post-truth, where any sort of conversations, especially political, don't embrace the rhetorical normalcy and has a motif to wave a discombobulating signal towards the society by using media as a tool, it's the people who has to discriminate the signal from the noise to somebody in particular to the society. The contemporary media situation needs fact-checkers as delegate. The idea of fact-checking can be a serious turn around of this situation if the common public can transform themselves as active recipients and not as the passive consumers of information. While media with the help of digital intelligence provides us an array of information based on our likes and choices and restricts ourselves from questioning about the truthfulness of it by showing us the repetition through different opinions, a positive engagement in open conversations amongst people can alter that situation. Because, an open forum of conversation regarding any confusion can lead us to variegated ways of solution by turning several opinions under the same umbrella which helps to research on the verisimilitude of any objective truth. According to Macintyre (2018),

"One of the most important ways to fight post truth is to fight it within ourselves.

Whether we are liberals or conservatives, we are all prone to the sorts of cognitive biases that can lead to post-truth" (p. 162).

The more we question by not believing what is being portrayed the more we would be able to value our active participation in fact-checking processes and grapple with the hobbled condition of social media which has fostered an obnoxious battle between the truth and technology.

\section{Notes}

1. By 'economies of scale' Davis intends to put forward a notion of efficiency that is generated through economic exchange.

2. Etinne Lombard (1869-1920), was a French otolaryngologist who came out with his ground-breaking findings on the raised voiced phenomena in 1909 and published the paper two years later in 1911 as 'Le signe de l'elevation de la voix' ('The sign of the elevation of the voice'). His obsrvation on the effect of the elevation of voice is termed as 'Lombard Effect'.

\section{Reference}

Arendt, H. (1962). The Origins of Totalitarianism. Meridian Books.

Asian News International [@ANI]. (2018, October 28). Shashi Tharoor in Bengaluru, says,

"There's an extraordinarily striking metaphor expressed by an unnamed RSS source to a journalist [Tweet]. Twitter. https://twitter.com/ANI/status/1056454318272995328

Black, M. (1985). The Prevalence of Humbug and Other Essays. Cornell University Press.

Burke, E., Canavan, F., \& Payne, E. J. (1999). Select Works of Edmund Burke: Letters On a Regicide Peace. Liberty Fund.

Davis, E. (2018). Post-Truth: Why We Have Reached Peak Bullshit and What We Can Do About It. Little Brown.

Frankfurt, H. (2009). On Bullshit. Princeton University Press.

Kalpokas, I. (2018). A Political Theory of Post-Truth. Springer.

Lansdown, R. (2006). "Our Fault, Not Theirs": The Future of the Humanities. Profession, 119-128. https://www.jstor.org/stable/25595835 
McIntyre, L. (2018). Post-Truth. MIT Press.

Menand, L. (2005). Dangers within and Without. Profession, 10-17. https://www.jstor.org/stable/25595793

Orwell, G. (2010). Politics and the English Language and Other Essays. Benediction Classics.

Rabin-Havt, A. (2016). Lies, Incorporated: The World of Post-Truth Politics. Knopf Doubleday Publishing Group.

Trollop, A. (1995). The Way We Live Now. Wordsworth Editions.

Twain, M. (2014). Following the Equator. Simon and Schuster.

\section{Bio-note}

Mr. Shankhadeep Chattopadhyay earned his B.A in English from Ramakrishna Mission Residential College, Narendrapur (Autonomous), his M.A in English from Banaras Hindu University and is pursuing his Ph.D. from Banaras Hindu University, Varanasi. His doctoral research deals with the poetics of countercultural song in performance in 1960s America. His interests include music and literature, urban geography, spatial and cultural studies, digitalhumanities, postmodernism and creative writing. He was a former full-time writer for the Performing Arts column in Blouinartinfo.com and served the post of an English Language Assessor in Trivium Education Pvt. Ltd. Shankhadeep has been invited and presented his contribution on several national and international conferences in India and abroad. He often engages himself in several interdisciplinary debate sessions and quiz competitions held at state and national level. Shankhadeep is a creative writer at heart, a devout traveller and a classic-rock aficionado.

Email Id: shankhamanu@gmail.com 